\title{
En bien de la aldea y el agro
}

España está construída sobre el funclamento de sus aldeas campesinas. La población agricola española es muy superior a la industrial, y hasta sus ciudades se pierden en la tierra de labor, casi siempre sin suburbios ni arrabales, o de otra forma dicho, los campos llegan hasta los mismos confines de la ciudad, y los rebasan como queriendo apoderarse de ellos. Hoy por hoy, la base económica de nuestra patria reside en los blancos pueblos perdidos en las llanuras, aquellos tristes y sombríos pueblos donde la ciudad se detiene tan sólo para admirar el estoicismo de quienes se afanan en las ingratas tareas agrícolas. Cuanto pretenda hacerse en torno a una ordenación económica ha de tener en cuenta esa verdad que forma nuestra masa campesina apiñada en torno a los elementos más reales de las instituciones sociales todas: la parroquia, el municipio y la familia. Estos tres elementos básicos de toda organización superior se enraizan con una fuerza máxima en las aldeas. Tengamos por otra parte en cuenta que en los tres, el individuo se somete a la autoridad del jefe del grupo de una forma directa, sin intermediarios, con lo que su fuerza de coacción es mucho mayor.

En la aldea, el párroco, el alcalde y el cabeza de familia por lo reducido del número de individuos en los dos primeros casos y por las especiales condiciones en que se desarrolla el trabajo en el campo, en el último ejercen su imperio de una forma absoluta y preponderante. En la ciudad, la ligazón del jefe con los componentes del grupo es bien escasa. Le basta una simple ojeada al buen cura rural durante la celebración de la misa, para saber quienes son los que no han cumplido con el precepto divino, y más tarde amonestarles al corazón con la caridad de Cristo. Es directamente el alcalde en 
el pequeño municipio quien reprende severamente a ios iniractores de las Ordenanzas, a ios muchachos que entorpecen con sus juegos el tránsio por las calles, a ios mozos que aiborotan excesivamente en sus dias de expansión. $Y$ es el padre de la familia aldeana quien pueçe - bien diferentemente de cuanto ocurre en la ciudad-, rodeado de sus descendientes, aconsejarles en la ciencia de la vida, reprenderles y premiarles, orientarles en sus trabajos y en sus empresas con la sabiduría de la vida, esa que no se aprende en los libros ni en las Universidades, sino en el transcurrir cansado y atosigante de los años. ¡Quizá por mantener con su pristina pureza estos tres elementos vitales la aldea se ha salvado de la infección que ha hecho presa en el mundo!

La ciudad vive su vida, agitada y febril, desocupada y ajena a las preocupaciones de capital importancia de su hermana inferior, la aldea. Craso error. Ciudad y aldea se necesitan mutuamente para una existencia digna y feliz. En el todo nacional en que forman, los problemas de la una son los problemas de la otra, y la resolución de los de la una significa la resolución de los de la otra. La aldea encuentra expansión y salida de los productos que exceden a su consumo mediante la ciudad. Y la ciudad, por esta prestación, da a la aldea los instrumentos mecánicos de su trabajo, las producciones industriales, y la conciencia de la Patria superior en que todos se hermanan. Mal hace la ciudad apartándose de la aldea, por que por encima de estos productos materiales, proporciona a la Patria el elemento capital para toda obra: el hombre. Ella es quien nutre los seminarios y cuadros inferiores del Ejército. Como nadie siente en todo su valor lo que la Patria es, porque como nadie valora cada pedazo de su suelo, en el que amorosamente cuidado le dará en sazón los frutos de su vientre con generosa entrega, como la de la mujer que nos dà con el hijo la alegría sana de una nueva rama en el viejo tronco familiar, mientras se estremecen los dolores del alumbramiento.

Ante la amenaza de la Patria en peligro la aldea se apresta presurosa a ofrendar los números ignorados de las filas del Ejército, que en su unidad forman las filas compactas de las grandes unidades de guerra. El campesino de todas las patrias, pero espe- 
cialmenté este campesino español tan sufrido, que ha dormido escasas horas en las noches de faena, y que ha pasado el día al duro sol manejando sin desîallecimiento - con la unción sagrada de una sublime misión - la guadaña o la hoz, o el arado, es el que, soldado, aguanta con sin igual porfía la fatiga y la dureza de la vida de campaña. El soldado campesino, retraído y callado, que no pide ni exige nada, y que cuando le mandan agradece, es el mejor fundamento de los Ejércitos. El sólo sabe que hay que defender aquel pedazo de tierra que está regado con el sudor de sus mayores, y que manos extrañas pretenden violentarle, que la vieja bandera sacada por el Municipio en las solemnes procesiones pretenden rasgarla manos extrañas, y armado de coraje y una fe inigualable sabe morir con un extraño estoicismo cristiano, que no es otra cosa que la entrega de su juventud al martirio. Cisneros, aquel gran monje que hizo realidad permanente su entrega al servicio de la Religión y de la Patria, franciscano y político, mitad monje y mitad soldado, sabedor de estas verdades, formó aquellas famosas Milicias campesinas que fueron la expresión más exacta del alma del labrador español.

$Y$ el campo da, como una de sus mejores flores, el cura rural. Los seminarios son en su mayoría cubiertos por muchachos de las aldeas que sueñan con tener al Dios mismo en sus manos y hacer el bien como todo objetivo. Nuestros curas rurales merecen que España entera les agradezca su misión de consuelo y de paz entre las gentes humildes de los campos. Su figura — sobre todo hoy que los rojos esquilmaron tantas vidas sacerdotales $\mathrm{y}$ han de acudir a tantos lugares- expuesta al viento y al sol, a la lluvia y a los fríos, se muestra presurosa en los caminos, y a leguas y leguas de su casa rectoral ha de extender el dulce consuelo de la bendición que Dios da por su brazo, mientras pronuncia las dulces palabras de la reconciliación. Es infatigable en su ir y venir para hacer el bien y repartir su miseria entre los desgraciados que le rodean. $Y$ a donde no llega su pan llega su palabra de conformidad y aliento, que es rocío que refresca las almas secas por el duro sol de la vida. Con una bendición recorre en su sagrado ministerio los caminos que enlazan los lugares y poblados el cưra de aldea, con 
su paraguas rojo, su bonete y su misal bajo el brazo. Padre de todos, hermano de todos, las miserias de todos son sus miserias, por eso su miseria es mayor que la de todos. Forjados en la sencillez y austeridad de la casa labradora, donde los hombres son a más del paisaje, al que obedecen, y así se acuestan con las gallinas y se levantan con el sol, los curas rurales, salidos de la aldea, van a la aldea a formar conciencias y enseñar virtudes.

Pero donde la aldea tiene su mayor timbre de gloria es en la familia: la numerosa familia aldeana, no restringida a teorías anticoncepcionistas, que por ser antinaturales no tienen razón de ser donde todo es naturalidad; en la que el primado es ejercido como una autoridad ejemplar, a la que se someten respetuosamente todos, desde el más insignificante zagal hasta el hijo casado con descendencia ya "moza". La quiebra de este poder del jefe de familia es sentida trágicamente en la vida moderna. El hombre que no se siente sometido al más dulce yugo y a la primera autoridad natural, ya que de sus padres procede, es difícil que luego sienta con agrado el sometimiento a quienes están encargados como autoridades, no por fuerza de la sangre, sino por la de la ley, de su cuidado y bien. El hombre sin freno, sin atadura a una cabeza rectora, sintiendo el placer de revolcarse por donde le venga en gana, como los potros en la pradera, no tardará en alzarse contra quienes por el escaso cuidado que de él tuvieron, no venera, ama y respeta como debiera.

La aldea da con la familia hombres, y hombres de un valor efectivo para la Patria. La familia se resquebraja en la ciudad, donde todo es transitorio y fugaz, mientras la aldea pide asentamiento y quietud. La mujer de la capital, equiparada en derechos al hombre que como él trabaja, fuma y bebe, siente como la más horrible y desagradable de las condiciones la de madre. El ser madre, primero los cuidados del parto, y más tarde el de los hijos, la imposibitan el asistir a reuniones y fiestas. El hijo no es para ella la alegria. de la casa, sino el estorbo que la impide una vida libre; porque cuando de libertad se ha hablado, la mujer ha llegado a tal emancipación, que parece que la historia se tambalea, va a dar la vuelta y vamos a encontrarnos de nuevo en la fase difícil del matriarcado, 
en la que la mujer lo es todo, y en aquella organización primitiva de la sociedad y de la economía, cultiva la tierra y dirige la familia. Este tambaleo de la historia anuncia un decaimiento, volvemos atrás. La ciudad ha de aprender en esto de esas familias aldeanas, donde no tener descendencia que continúe gozando la tierra es un baldón.

La ciudad es un espejismo que con sus taras morbosas llama constantemente la atención al campo. La ciudad es vida fácil y ligera, por eso tan horriblemente tienta al campo con más saña y perfidia que aquella con que la serpiente presentó a Eva la manzana podrida como sana y jugosa en el Paraíso. La ciudad ofrece un influjo poderoso sobre el campesino, y ante ello surge el problema de la desaparición de esa reserva de virtudes que constituye. El acicate en el abandono del campo es que el labrador desea que su hijo no siga la esclavitud a la tierra que él ha soportado, y así toda su ansia es introducirlo de un modo $\mathfrak{u}$ otro en la siudad, que vista como un señor, un señor falsificado desde luego, porque ningún señorito puede compararse a la grandeza del "amo" disponiendo las cosas de su hacienda en el agro. La ciudad pronto desvía sus promesas y ofrecimientos, y allí está bella y difícil, como una meta inaccesible, dejando en el camino muchas vidas trituradas y deshechas. Pero una vez en la ciudad "el aldeano prefiere morir sobre el asfalto de las calles que regresar al campo. $\mathrm{Y}$ no lo liberta ni siquiera el asco de esa magnificencia, el hastío de tanta luz y tanto color, el tædium vitæ, que de tantos se apodera al fin". (Spengler: La decadencia de Occidcntc.)

\section{LA CIUDAD Y EL CANPO}

La ciudad y el campo se distancian cada día más. ¿Dónde está la causa de ese divorcio espiritual? La ciudad técnica e intelectualismo vive una vida agitada. Lo que ayer fué gran avance y conquista científica, hoy no es nada. Cada momento parece superarse, sintiendo el orgullo de cuanto ha llegado a ser, que bien se conoce en esa superior:dad con que el habitante de la ciudad enseña al aldeano los grandes edificios, las avenidas, los parques y espectáculos de atracción. Por el contrario, la aldea ha quedado estancada 
en su quehacer de hace siglos y edades, encerrada en su mutismo. Podemos decir que la ciudad habla un lenguaje desconocido y oscuro para la aldea, que se expresa en un idioma lejano, casi unido al nacimiento del hombre. La gran ciudad progresando constantemente y la aldea asentada en su primitiva sustancia, se han distanciado de tal forma que ya no pueden encontrarse. La ciudad no entiende los problemas de la aldea, el que haya habido una granizada, una sequía, una helada..., y tan sólo se lamenta cuando se encuentra en el mercado con los productos más caros. “ $i$ Pero estos campesinos...! ¿ Hasta dónde nos van a hacer pagar frutas y verduras?"

$Y$ el campo, la aldea no sabe de urbanismo, de estética arquitectónica, ni de Universidades ni Museos. Para ella todo eso son cosas de otro mundo, algo que sólo puede darse a almas escogidas. Pero a la hora de repartir las cargas entre todos los nacionales, el campesino habrá de abrir su bolsa igual que cualquier provinciano que se beneficiará de los servicios y obras públicas.

Es necesario que la ciudad, que los técnicos rindan un definitivo servicio al campo. Vamos a llevar a la aldea un lenguaje que sea suyo y nuestro, vamos a hablarle de sus cosas, de sus problemas, con un sentido viejo y nuevo; las faenas de la tierra son esencialmente las mismas, pero digámosle como se realizan en forma más ventajosa, de qué manera obtendrán un mayor rendimiento, cómo se devuelven al suelo los elementos necesarios para su vida. Hagámosle ver que nuestro lenguaje ininteligible puede ser comprendido si se dice con el fuego de una misma pasión, de un mismo amor, de una misma caridad, como entendían a los Apóstoles los peregrinos de las más lejanas latitudes, porque la gracia del Espíritu Santo les había sido comunicada. En el santo amor a España han de encontrarse los corazones de la ciudad y el campo, para que conociéndose se entiendan y entendiéndose se amen.

Es necesario que vayamos al campo con el corazón lleno de generosidades. De nada serviría tanta teoría, tanto estudio, tanto cálculo, si quedan reducidos a los estrechos límites de lo que constituyen los núcleos puramente científicos. Todo progreso técnico y social debe de tener una honda repercusión en el campo. Hay que 
sacar al agro español -como decía el gran descontento Joaquín Costa - de la agricultura del siglo xiv. La revolución que está alcanzando a la ciudad, esto es, al obrero, ha de llegar al campesino. No es sólo algo conveniente, sino una ineludible obligación al revolucionar la aldea; revolucionar el campo; variar su estructura técnica, juridica y social, e inyectarle toda la fuerza suficiente para que ande de una vez todo el estancamiento de los últimos siglos.

Esta revolución del campo es algo que hay que hacer no sólo por un sano criterio de justicia social, sino que nos viene obligando egoísticamente. Mientras nuestra Patria no pueda alcanzar un rango comercial digno en el exterior, que sólo una intensificación en la labor agrícola puede darle, no podrán arribar a nuestra España las materias primas para la implantación de la industria que necesita apremiantemente, y sin ellas es imposible mantener un Ejército, una Marina y una Aviación que hagan pesar nuestra intervención en el mundo. Hemos de afianzarnos en lo que tenemos, para sobre este espacio volar a más altas empresas. La revolución del campo es la revolución de España, sin ella no hay revolución posible. El campo, por otra parte, no admite paliativos ni componendas, requiere una revolución rígida y a rajatabla en la que no se respete nada que no haya que respetar. Saludemos, pues, con alegría a la iniciación de esta labor, que alborea con la promulgación de la ley de Justicia Municipal.

Toda política que no aspire a elevar la aldea al siglo $\mathrm{xx}$ es inútil. El afán de los gobernantes ha sido hasta hoy la urbanización de las grandes ciudades, la construcción de magníficas avenidas, edificios, parques y jardines. Todo le daba más popularidad para su carrera política, que llevar al campo la justicia de Dios y la gracia de la civilización y la cultura. El éxito del gobernante es más fácil en las grandes aglomeraciones urbanas, dueñas de la prensa, donde resuenan más los hechos que en las diseminadas aldeas. Tan sólo se acordaron los políticos de los pueblos cuando necesitaban votos para su elección de diputado, y entonces ofrecían la carretera, el puente, los pequeños espejuelos que alucinaban los intereses locales, pero nunca les fué dada la justicia que piden los campos españoles, abandonados al agricultor sin una dirección y cuidado del estudioso 
de la capital, que no quiere ir a la aldea, que a muchos, pese a su profesión, le resulta desagradable e incómodo.

La revolución a que aspiramos para el campo no es una asonada, ni una marcha con guadañas y hoces en alto. La revolución que salvará al agro español es la mutación completa de su forma de ser, dotándolo de instituciones que varíen sus problemas, dándole una estructura en la que resplandezca el sol de la justicia.

\section{Preocupación RURAL}

La preocupación rural se ha metido de lleno en el alma de nuestros políticos de hoy. Ahí está el Instituto de Estudios de Administración Local como una prueba evidente y certera de ello. Los avances por el Instituto logrados a través de su Revista; de la preparación técnica de funcionarios capacitados que, repletos de un ardor misionero, se esparcen por todas las tierras de España para mejorar sus cosas; de los cursos especializados para quienes han de colaborar en el engrandecimiento y embellecimiento de nuestros municipios, es buena prueba de que ha calado por fin hondo en las mentes la preocupación rural, al mantener ese foco sagrado de tradiciones y costumbres, que pueda alentar generosamente la vida de la ciudad, pero de ahora en adelante con una diferencia esencial con lo que hasta aquí ha ocurrido; esa ayuda a la ciudad, esa paz necesaria que a la aldea va a buscar para descansar el hombre de la capital será contrapesada por la participación del agro en las mejoras de la civilización que puedan beneficiarla.

Hay que ir a la aldea con la pasión del amor al municipio y sin las trabas de quien palpa a cada hora los inconvenientes de realizar las ideas, más difíciles de llevar a la práctica cuanto más grandiosas son. Pero hacen falta en esta coyuntura histórica brazos esforzados que no se desmayen ante la inmensidad de las dificultades, y que, aún más, se crezcan ante ellas. Lo que importa es que el corazón sienta con calor la grandeza de la empresa a realizar, que ya la inteligencia, ayudada por la tozudez hispana - traducción vulgar de la fe-, arbitrará los caminos precisos para descan- 
sar en la consecución de su fin. Si es que el ideal de superación puede hallar el descanso, pues siempre la meta está más allá.

Nuestra pasión por las cosas del campo está fundada en el convencimiento de su influencia en el ser todo de la Patria. La nación es bastante de su geografía, sin que con esto pretendamos negar la potencia creadora del hombre, pero la geografía sólo es el campo, porque la geografía pide variedad y diversidad, del azul intenso del cielo, al pardo de las tierras, al verde de los árboles, el esmalte de sus árboles floridos, y color indefinido de los tranquilos y sencillos regatos. La ciudad es amorfa, masa gris indefinida, sin geografía, con moles de cemento a las que se hace referencia por el número sin gracia y no por sus contornos. La ciudad son casas, el campo son montes, valles, colinas, nubes, cielo, horizontes, lagos... Una nación campesina tendrá fuerza creadora, potencia genial para inundar el mundo de sus producciones, de sus pensamientos, al que en definitiva sirven la fuerza y el poder.

Sin llegar a Montesquieu cuando en Del espiritu de las leyes establece relaciones entre el despotismo y el clima cálido, y entre la libertad y el terreno montañoso, dentro de ciertos límites ponderamos el valor de lo geográfico sobre lo que una nación y sus nacionales sean. El suelo señala al hombre, más o menos, cuáles han de ser sus condiciones de vida. Los hábitos de sobriedad y resistencia -dice Ruiz del Castillo- son simultáneos con los obstáculos que oponen el medio físico. Y nuestra nación, eminentemente campesina, con una historia que sólo almas que sintieron la inmensidad y grandezas de sus tierras pudiera crear, no puede apartarse del agro, ha de ir a él con fórmula solemne de salvación.

Puestos a dotar a las aldeas españolas de un servicio que les sea necesario, fijándonos en sus especiales características agrícolas, hemos hecho un estudio que recoge la voz sentida a través de tantas generaciones, y que como nadie ha resonado, ésta que fué compañera del labrador en los campos de batalla, que escuchó de sus labios sencillos los problemas y que aprendió a amar a la madre tierra cuando, pegado a ella, sintió a su alrededor — no sin escalofrío- el girar alocado de la muerte envuelta en los disparos enemigos, a la que vió admitir en su seno, con generosa compasión, al 
compañero héroe, caido para alzarse hasta la altura inaccesible de los cielos.

La ciudad va a dar al campo, en este proyecto nuestro, sus técnicos, pero capitalmente la aldea va a extraer los medios precisos para resolverse lo que a ella le interesa, lo que está urgiendo, para alzarse, para dignificarse, para revalorizarse. Fiados en la importancia nacional, de primer orden, de la productividad agrícola para la existencia de un frente económico que oponer en el mercado internacional, expresamos la conveniencia de auxilios del Estado y la provincia, esa entidad muerta que es preciso reanimar o fulminar su inmediata desintegración, para dar paso al nacimiento de otra entidad natural, cargada de adhesiones y entusiasmos, que es la región, la que empapada de glorias históricas que empalman en la Reconquista, une en unos mismos problemas a quienes habitan una comarca con identidad geográfica.

El proyecto de servicio municipal que presentamos es quizá el de más capital importancia nacional. A pesar de su carácter puramente local. Asentado en los pequeños núcleos de las aldeas rurales, tendiendo a llevar un poco de luz a las almas campesinas, significa un avance de trascendental importancia en la producción agrícola, y por ende en la economía patria toda.

Tiene el proyecto, en su concepción, dos bases sustanciales. La una tiende a la enseñanza profesional, y de los conocimientos gene-rales necesarios para el desenvolvimiento del hombre en la vida. No se han tenido tan sólo en cuenta, pues a pesar, como es claro, de ser la principal de las enseñanzas a prestar, la parte técnica y práctica, relativa al cultivo y a la ganadería, sino que se ha dado entrada a las enseñanzas de religión, que no sean muy elevadas, pero sí muy profundas, para que arraiguen sobre la buena disposición de los campesinos y los infunde fe y esperanza en una vida ultraterrena. Si para estas enseñanzas se dispone de sacerdotes hábiles y encariñados con su tarea, nos atrevemos a afirmar un resurgir del catolicismo, que impregne la vida toda de España, como en otros tiempos. La enseñanza de la ortografía permitiría al agricultor mantener correspondencia con sus proveedores y compradores de una manera digna; las sencillas matemáticas a llevar su contabi- 
lidad y conocer, sin auxilio de extraños, el conocimiento de su hacienda; la geografía les ayudaría a conocer la tierra sobre la que ponen sus pies; la historia patria las glorias nacionales, para que la amen más y sientan ansias de ser, desde el puesto que en la sociedad les corresponde, un héroe más; las historias y tradiciones locales y regionales pondrían en pie su ardor por el pedazo de tierra que les vió nacer, y valorarían con un sentido nuevo cada una de las piedras que componen el pueblo.

Todas estas enseñanzas habrían de darse de un modo agradable, que atraiga a los alumnos y los haga seguir con atención e interés todas las disciplinas.

La enseñanza profesional ocuparía la parte principal de los cursos, orientándose de un modo práctico, abarcando las disciplinas necesarias para conseguir una generación de labradores nuevos que sean los primeros interesados en llevar a sus campos las mejoras que en la "Escuela de capataces y gañanes" aprendieron. No se aspirará tan sólo a formar aprendices de una teoría rutinaria y enteca, sino verdaderos soldados que empuñen, como un arma nueva y con un brío nuevo, los viejos y los modernos instrumentos y prácticas agrícolas.

Otros dos puntos habrian de ser evidenciados en esta Escuela: las relaciones de la agricultura con la ganadería y el arbolado, sus ventajas y sus mejores servicios y aprovechamientos.

La segunda base esencial es el "Servicio de perfeccionamiento agrícola", a quien ha de corresponder la renovación del agro español. "Hay que abandonar a la estepa - hemos oído decir muchas veces- tierras improductivas en las que el labrador se desangra para conseguir extraerles jugo, y no logra sino escasos resultados, $y$, por el contrario, es preciso explotar muchos terrenos hoy abandonados, mejorar otros y salvar los terrenos pantanosos". Pues bìen, esta es la labor que se encarga al "Servicio de Perfeccionamiento agrícola". Añadamos a esto la necesidad de señalar con un criterio científico la producción que ha de dar un mayor rendimiento por la especial composición de la tierra de la comarca a que alcance la Agrupación intermunicipal, los abonos que le son más neceșarios $y$ las labores preferibles, aparte de seleccionar las semillas. 
En cuanto a la ganadería y animales domésticos y de labor, se ha de hacer que cada región posea las especies que procuren un mayor rendimiento con un mínimo de coste al ponerlas en relación con el medio ambiente.

El tema de repoblación forestal ha de ser estudiado adecuadamente.

El trabajo del "Servicio de perfeccionamiento agrícola" es principalmente un trabajo de experimentación y de laboratorio. En una palabra, es la técnica puesta con todas sus consecuencias a laborar adecuadamente por hacer prosperar las condiciones del campo; porque el abandono en que ha vivido hasta aquí el agro no puede continuar. La aldea es un agrupamiento de hombres que viven de la productividad de su suelo; si las condiciones favorables de éste faltan, la aldea se disuelve por emigración de los que la componen. Ha de cuidarse la tierra con un cuidado exquisito, pues de sus ubres fecundas vive la totalidad del pueblo español. La pasividad es una traición imperdonable. $\mathrm{Y}$ al igual que existe un médico para cuidar: a las personas y un veterinario para cuidar a los animales, debe existir, comarcalmente, una organización técnica agraria para cuidar y hacer que progresen los campos. Este es el camino, el principio y el fin para una obra fecunda, obra hispánica, que llevaría consigo el aumento de la población, y con ello a una mayor potencialidad patria. Hay que defender, por encima de todo, que el cuidado de los campos necesita técnicos que de cerca vigilen sus variaciones.

Ha de estimularse también la mejora de la producción mediante la celebración de concursos y exposiciones que remuevan la competencia.

\section{LAS AGRUPACIONES Y SUS REALIZADORES}

Al señalar quiénes habían de ser los que dieran realidad a estos servicios hemos indicado la necesidad de introducir en la vida aldeana dos nuevos elementos, hasta ahora casi apartada de ella en absoluto, sin una explicación lógica: el ingeniero agrónomo y el perito agrícola. Se llama a colaborar con una misión específica al veterinario. La dirección espiritual se consigue dando cabida en el 
profesorado al párroco, y la enseñanza general rudimentaria que abra nuevos horizontes a los campesinos, será regida por los maestros locales.

Atendiendo a los gastos del profesorado, únicamente el ingeniero agrónomo y el perito agrícola habrán de ser retribuídos especialmente, ya que el párroco, el veterinario y el maestro serán recompensados por gratificación.

Como extensión del servicio se señala la comarca agrícola, porque es hora de que se proclame valientemente y sin rodeos la fatal división administrattiva de España, que sólo criterios miopes pudieron propugnar en tiempos de un desconcertante liberalismo, ya que está hecha atendiendo a las posibilidades del caciquismo. Desmontando como estamos los años de desintegración para alcanzar la solución justa de los problemas con un criterio nacional, hemos de atacar con punta de lanza la división provincial y de partidos judiciales, dos agrupaciones inseguras y faltas de naturalidad, hechas a çapricho y con vistas a las actas parlamentarias. Las entidades locales menores y los municipios, por el contrario, son instituciones naturales, y necesidades permanentemente sentidas en la conciencia individual. Así también la división en regiones.

Pensemos seriamente que la unidad más sentida por los hombres es la que nace de sus idénticos intereses en torno a problemas económicos y profesionales. Una entidad de tal naturaleza reuniría en sí las adhesiones más profundas de cuantos la formaran, porque entenderían que en su defensa lo que defendían era su hacienda, y con ello el porvenir de los suyos. Una agrupación así habría de reunir los intereses comarcales agrícolas, es decir, los pueblos que sostengan relaciones por necesaria comunidad de pastos, riegos, etc.

Estas comarcas agrícolas serían la base de nuestras Agrupaciones intermunicipales agrícolas, y con ello se iniciaba la evolución hacia una división administrativa española más de acuerdo con la naturaleza de su suelo. Reunimos algo que está unido por la indiscutible voluntad del Creador, al señalar un determinado territorio, unas mismas condiciones de vida y unos idénticos problemas.

En el orden de la recaudación de los recursos para llevar a cabo las Agrupaciones, se ha tenido en cuenta los gastos de primer esta- 
blecimiento y los de entretenimiento. Estos últimos han de ser mínimos, puesto que aun con la módica cuota que ha de señalarse por las enseñanzas, los derechos de tasas por la utilización de determinados servicios y los rendimientos que se obtengan, se estará casi en ocasión de nivelar el presupuesto. Para ambos gastos de establecimiento y de entretenimiento se ha pensado en las subvenciones que del Estado, la provincia y los municipios pudiera recibir este especial servicio.

Donde ha de necesițarse una mayor cantidad, es en los gastos de establecimiento, pero pensemos en aportaciones del Ministerio de Agricultura, de las Diputaciones, de las Cámaras Agrícolas, de los particulares... y hasta donde este no llegue, debe de alcanzar la emisión de una deuda, para cuya amortización se destinaran todos los años las cantidades precisas, llevándose especial contabilidad para conocer con exactitud la situación en cada momento de lo adeudado.

He àquí lạ exposición de cuanto creemos puede hacer hondo surco en la economía española. Queremos señalar aún un punto de vista importantísimo, como es el humano. Hace falta el hombre para cada comarca, que, apasionadamente, sin miedo a las dificultades, los recelos y las críticas, se entregue generosamente a la obra, que la viva, que la sienta como algo de su propia carne. Porque aquí donde se juegan factores de tan alto valor espiritual, el hombre ha de desprenderse de su envoltura para no ser sino puro espíritu. Tal ha de ser el Presidente de la Agrupación intermunicipal, prototipo y ejemplo de los Alcaldes que los municipios españoles necesitan. Junto a él llamamos a colaborar, exclusivamente, a labradores y a. quienes - por su razón de trato directo con la tierra- conocen sus problemas y aspiran a resolverlos. Los Concejales que representen a los Ayuntamientos habrán de reunir estas condiciones. La Junta. de Agrupación, rectora de la vida del servicio, tendría una serie de prerrogativas que hicieran eficiente su labor.

Al frente de cada una de las Secciones debería de haber una Junta, que presidiera un Concejal de la Junta de la Agrupación, y de la que formaran parte técnicos e interesados.

Para la realización de esta obra nos atrevemos a formular las siguientes normas, que pudieran servir para la constitución de Agru- 
paciones intermunicipales para la realización de servicios con fines agrícolas.

\section{NORMAS PREVIAS}

De acuerdo con lo que dispone la Base XXI de la Ley de Bases para la Ley Municipal, de Io de julio de 1935, y artículos 23, Io2 -apartado F, e- y 107 de la Ley Municipal de $3^{\text {I de octubre }}$ de 1935 , teniendo en cuenta los artículos números 16 , I7 y i9 del artículo 150 del derogado Libro Primero del Estatuto Municipal de 8 de marzo de I924, creemos conveniente la constitución de Agrupaciones intermunicipales, de carácter voluntario, que reunan a los distintos municipios rurales de una misma comarca agrícola, bajo la denominación de "Agrupación intermunicipal agrícola...", con el nombre que se adopte, y que podrá ser el del Ayuntamiento que sea cabeza de la misma, u otra cualquiera que haga referencia a los fines para los que se constituye. Estos fines serán:

I. Aumentar el nivel cultural de la población agrícola.

2. Mejora de las condiciones de trabajo de los campesinos.

$3^{\circ}$ Enseñanza técnica y profesional de los labradores.

$4^{\circ}$ Conseguir un mayor rendimiento del suelo y del ganado.

Para la constitución de la Agrupación intermunicipal de carácter voluntario y su funcionamiento, se habrán de tener en cuenta los preceptos contenidos en el artículo 23 y siguientes de la Ley Municipal, y los correspondientes del Reglamento sobre población y términos municipales. La dirección de la Agrupación sería ejercida por el Alcalde del Ayuntamiento promotor de la misma, o el de aquel municipio que por especiales circunstancias merezca ser cabeza de la institución. Todos los Concejales que formaran la Junta de la Agrupación deberían de ser agricultores, considerándose como tales a los que posean y administren la tierra directamente o trabajen en ella como técnicos, capataces y gañanes, o simples jornaleros.

La Junta de la Agrupación tendría las siguientes atribuciones:

I. La formación de los Estatutos a que se refieren los artículos 24,25 y 26 de la Ley Municipal, y $8 .^{\circ}$ del Reglamento sobre población y términos municipales, de 2 de julio de 1924 .

2. ${ }^{\circ}$ La recaudación de medios para el establecimiento de los 
servicios de la Agrupación, y su conservación y entretenimiento, y su empleo con la autonomía a que se refiere el artículo $3 .^{\circ}$ de la Ley Municipal en su párrafo segundo.

3. La inspección y alta dirección de los servicios de la Agrupación.

$4^{\circ} \quad$ Cuidar de que se cumplan los fines para que se creó.

La Agrupación intermunicipal podría alterarse por separación de alguno de sus miembros, entendiéndose en este caso que renuncia a todo derecho; disolución de alguno o algunos de los municipios que la componen y entrada de nuevos miembros en la Agrupación en las condiciones que se le impongan.

La Agrupación podría disolverse por acuerdo en firme de las dos terceras partes de los municipios que la formen y por liquidación con déficit de tres presupuestos seguidos si no se arbitran los medios precisos para la restauración de su hacienda en los dos siguientes.

Una vez disuelta la Agrupación intermunicipal, los Ayuntamientos que la formaran tendrían derecho a una parte de los beneficios o estarían obligados a contribuir a las cargas, proporcionalmente, a las respectivas aportaciones.

\section{LOS SERVICIOS A PRESTAR}

Los servicios que prestarían las Agrupaciones intermunicipales agrícolas de carácter voluntario habrían de ser:

Escuela de Capataces y gañanes, cuyo fin primordial sería la preparación práctica de los campesinos, que mejore las condiciones de trabajo y la productividad del suelo.

Servicio de perfeccionamiento agrícola, para el estudio de las especiales condiciones del suelo de la comarca, con el fin de realizar los cultivos más convenientes; mejorar sus condiciones de productividad, devolviéndole los elementos de que se encuentre falto; obtención de semillas favorables, y propagación de animales domésti$\cos \mathrm{y}$ de labor, en sus especies más sanas y ventajosas. 


\section{Escuela de CAPATACES Y GaÑanes}

La Escuela de capataces y gañanes tendería a la enseñanza práctica y experimental de una agricultura nueva, con el manejo de los modernos aparatos y maquinarias de trabajo, y siempre en relación con las especiales condiciones de la comarca donde se actúe. Haría conocer al labrador el modo de un empleo eficiente en los abonos y las condiciones a establecer entre la labranza y la cría del ganado.

Tendrían también los alumnos clases de Religión, Aritmética, Ortografía e Historia de España y de la comarca o región.

El profesorado podría estar compuesto por el Ingeniero agrónomo, Perito agrícola y Veterinario, para la parte profesional y técnica, y el Párroco de la localidad y Maestro para la enseñanza elemental rudimentaria.

La Escuela estaría dividida en dos secciones de cursos normales y abreviados. Concurririan a los primeros aquellos agricultores que pudieran seguir los cursos completos, y los segundos serían para aquellos a quienes sus quehaceres permanentes no les permitieran apartarse por mucho tiempo de la localidad. La duración de ambos cursos se fijaría en el Reglamento especial de la Escuela, de acuerdo con lo que resulte más conveniente para un menor perjuicio de los alumnos y su mayor aprovechamiento. El programa de las enseñanzas de ambos cursos contendría las disciplinas siguientes: agricultura, técnica agrícola, rudimentos de Botánica, anatomía y aprovechamiento de los animales domésticos y de labor, cuordinación agrícola, forestal y ganadera, Aritmética, Geografía, Ortografía, Historia de España y Local y Religión. El alcance de las materias a tratar serían fijados por un programa que, confeccionado por la Dirección de la Escuela, habría de ser aprobado por la Dirección General de Administración Local, previo informe del Ministerio de Agricultura.

Los programas de los cursos normal e intensivo serían distintos únicamente en cuanto a su contenido.

Los alumnos abonarían en concepto de matrícula pequeñas can- 
tidades que, destinadas al mantenimiento de la Escuela, servirian de estímulo para la asistencia y aplicación. Al finalizar el curso se entregarian a los alumnos diplomas que acrediten su asistencia a la Escuela, su competencia y aprovechamiento, sirviendo de garantía para quienes hubieran de contratarlos para realizar sus trabajos.

El profesorado de la Escuela se compondría de un ingeniero agrónomo, un perito agrícola, el veterinario, el maestro y el párroco de la localidad, o el sacerdote en quien delegue. La Escuela estaria regida por un Patronato que presidiría un Concejal componente de la Junta de la Agrupación, por ella designado; el Secretario de la Agrupación, que lo sería del Patronato; los dos mayores contribuyentes por contribución territorial, riqueza rústica, con residencia en la localidad, y todos los profesores. La dirección de la Escuela sería ejercida por el ingeniero agrónomo quien, con la Junta de profesores, entendería en cuanto se relacione con la parte técnica de la Escuela.

Con objeto de que las influencias beneficiosas de la Escuela pudieran esparcirse por todos los contornos de la Agrupación intermunicipal, mensualmente vendrían obligados el ingeniero agrónomo, el perito agrícola y el veterinario profesor de la Escuela, o el de la localidad respectiva, a dar tres conferencias en otros tantos municipios de la Agrupación sobre temas relacionados con el cuitivo, aplicándolos a la realidad de cada época.

Anualmente se establecerían concursos entre los pueblos de la Agrupación sobre arado y obtención de los productos de mejor calidad por un mayor cuidado y laboreo de las tierras, concediéndose premios.

\section{SERVicio de PERFECCIONAMIENTO AGRÍcola}

El "Servicio de perfeccionamiento agrícola" tendería:

I. A un mayor rendimiento de los campos sin destruir sus condiciones de productividad; $2 .^{\circ} \mathrm{A}$ un progresivo aumento de las condiciones de productividad en las tierras de la comarca; $3 .^{\circ} \mathrm{A}$ la obtención de las semillas más favorables al suelo; $4^{\circ}$ al estudio de los cultivos más beneficiosos; $5{ }^{\circ}$ A la cría, reproducción y obtención de las mejores especies de animales domésticos y de labor. 
Se realizarían los anteriores fines mediante campos de experimentación agrícola que, unidos a un trabajo de laboratorio, consiguieran adaptar al suelo las especies más beneficiosas a la comarca sin perder nunca de vista el alto interés superior de la economía nacional; la obtención autónoma, hasta donde sea posible, de los aboł nos necesarios; el depósito de semillas obtenidas por el Servicio y que se facilitarían a los agricultores a módicos precios por un "Servicio de Política Social"; la repoblación forestal, de acuerdo con las indicaciones del. Distrito Forestal; estaciones de viveros de árboles frutales; preservación y extinción de las plagas del campo; pues:ta en producción de terrenos no explotados; granja de animales domésticos y de labor; parada de animales reproductores, y facilitación de los animales necesarios a los agricultores a módicos precios.

El Servicio de perfeccionamiento agrícola sería dirigido por el ingeniero agrónomo y servido por el perito agrícola y el veterinario.

El personal administrativo y auxiliar que fuera imprescindiblemente necesario, sería nombrado a virtud de concurso $u$ oposición; cuidándose de una manera especial que la parte del presupuesto que se absorbiera fuera mínima.

\section{Medios ECONómrcos}

Atendiendo a su fin, mediatamente de interés nacional, pero in:mediatamente provechoso para las respectivas comarcas en las que se establezca, los recursos para las "Agrupaciones intermunicipales agrícolas" serían: para los gastos de primer establecimiento, aportaciones del Estado, de la provincia a que pertenecieran los Ayuntamientos y de los respectivos municipios de la Agrupación intermunicipal; los fondos que de cada año se reservaran para este fin por el Instituto Nacional de Previsión; donativos de particulares y empréstitos emitidos por la Agrupación intermunicipal conforme a lo dispuesto en el artículo $54 \mathrm{I}$ y siguientes del Estatutto Municipal: Para los gastos de conservación y entretenimiento: subvenciones auxilios de que habla el artículo 308 del Estatuto Municipal; arbi- 
trios con fines no fiscales del artículo 33 I del Estatuto; derechos y tasas por la prestación de determinados servicios, conforme a lo dispuesto en el artículo $374 y$ siguientes del mismo Cuerpo legal; el interés de los créditos concedidos; las ganacias mínimas que se permitirán en la facilitación de productos y en la venta de los obtenidos, y la matrícula de los alumnos de la Escuela de Capataces y Gañanes.

Cada año se formularía el correspondiente presupuesto que habría de contener los gastos fijos, aunque su cuantía fuera determinada, habiendo de figurar por separado los gastos de personal, con separación por sueldos y remuneraciones; los gastos de material, inventariable y no inventariable y los gastos diversos.

Las deudas que se contrajeran serían objeto de una contabilidad especial que permitiera en cada momento conocer exactamente la cuantía de las obligaciones de la Agrupación intermunicipal.

Para que la Agrupación intermunicipal pudiera promover recursos de cualquier índole, sería necesario el informe del Abogado del Estado de la provincia, y si siendo desfavorable se interpusiera o se ejercitara la acción correspondiente, recayendo fallo en contra de la Agrupación, serían responsables los que votaron el acuerdo en sentido positivo.

El Estado habría de conceder a las Agrupaciones así constituidas todas las exenciones y ventajas de que disfruten los Ayuntamientos, y habría de formar, mediante concurso, una "Agrupación intermunicipal agrícola modelo" que, adoptada por el Estado, sirviera de tipo e ideal para las que se fueran constituyendo.

Santiago Galindo Herrero 